\title{
Amplifying control RNA for RT-PCR applications by nucleic acid sequence based amplification (NASBA)
}

\author{
Sisko Tauriainen ${ }^{\mathrm{a}, *}$, Elina Dadu ${ }^{\mathrm{a}}$, Maarit Oikarinen ${ }^{\mathrm{a}}$, Sami Oikarinen ${ }^{\mathrm{a}}$, Heikki Hyöty a,b \\ ${ }^{a}$ Department of Virology, University of Tampere, Medical School, Biokatu 10, FIN-33520 Tampere, Finland \\ ${ }^{\mathrm{b}}$ Department of Clinical Microbiology, Center for Laboratory Medicine, Tampere University Hospital, Biokatu 4, FIN-33520 Tampere, Finland
}

Received 11 April 2005; received in revised form 22 September 2005; accepted 30 September 2005

Available online 28 November 2005

\begin{abstract}
Control RNA for RT-PCR applications was amplified by nucleic acid sequence based amplification (NASBA) using the NucliSens ${ }^{\circledR}$ Basic Kit. This method was used to construct positive control RNA for enterovirus, insulin, and G-protein RT-PCR, and for interferon- $\alpha$ real-time RT-PCR. The primers were designed to amplify identical RNA from RNA templates, which differs from the usual NASBA procedure, where opposite strand RNA is amplified from the target. This "inverse NASBA" method is easy to use and it does not require any expensive special equipment. The amplification reaction is done using a water bath and detection of amplified product by agarose gel electrophoresis. Generated RNA fragments were 195-714 bases long, of positive polarity and the amount of RNA was sufficient for thousands of RT-PCR reactions depending on the sensitivity of the RT-PCR.
\end{abstract}

(C) 2005 Elsevier B.V. All rights reserved.

Keywords: RNA amplification; NASBA; RT-PCR; Control RNA

\section{Introduction}

Nucleic acid sequence based amplification (NASBA) is an isothermal amplification method for RNA and it is designed to produce complementary RNA to the target (Compton, 1991). It is used mostly for diagnostic purposes in human and veterinary medicine and quality control of food products. Most of the applications are for detecting infective agents, like viruses and bacteria, for example HIV (de Baar et al., 2001; Kievits et al., 1991), CMV (Blok et al., 1998; Mengoli et al., 2004), West Nile virus (Lanciotti and Kerst, 2001), rabies (Sugiyama et al., 2003; Wacharapluesadee and Hemachudha, 2001), Mycoplasma pneumoniae (Loens et al., 2003a,b), Salmonella enterica and Listeria monocytogenes (Cook, 2003; D'Souza and Jaykus, 2003). It does not amplify DNA, because there is no denaturation step in the amplification. Therefore it is optimal for amplifying intronless genes like interferon- $\beta$ (Heim et al., 1998). However, in the amplification process small amounts of dsDNA and DNA:RNA hybrids are produced as by-products.

\footnotetext{
* Corresponding author. Tel.: +358 3 35518459; fax: +358 335518450 .

E-mail address: Sisko.Tauriainen@uta.fi (S. Tauriainen).
}

Amplification methods like RT-PCR, real-time RT-PCR and NASBA need specific positive control RNA, which is not always easily available. Especially in cases where the target is a tightly regulated gene product, which needs to be induced first, or viruses might be difficult to propagate. Also the use of a RNA fragment is safer than an infective virus like HIV, although for the first amplification the virus RNA is needed.

In this paper, we describe how the NASBA method can be used to produce specific positive control RNA for RTPCR applications. Four control RNA fragments were amplified: enterovirus, interferon- $\alpha 21$ (IFN- $\alpha 21$ ), insulin and G-protein. Primers for these amplifications were designed to produce positive strand RNA in contrast to the usual NASBA procedure, where opposite strand RNA is amplified from the target RNA. Therefore, we call this method "inverse NASBA". To achieve this, the T7 RNA polymerase promoter sequence was added to the forward primer (P2) instead of the reverse primer (P1).

\section{Materials and methods}

\subsection{Starting material and RNA isolation}

Enterovirus was amplified from purified Coxsackie virus B3 (CBV3) RNA (30 ng) obtained from cell culture supernatant 
Table 1

Primers used for inverse NASBA amplification of control RNA

\begin{tabular}{|c|c|}
\hline Application/primer name & Primer sequence \\
\hline \multicolumn{2}{|l|}{ Insulin } \\
\hline P1: SINSR & TTCCATCTCTCTCGGTGCAGGA \\
\hline P2: SINSF & AATTCTAATACGACTCACTATAGGGAGAAACATCACTGTCCTTCTGCCA \\
\hline \multicolumn{2}{|l|}{ Interferon- $\alpha 21$} \\
\hline P1: SIFA4R & CATGGTCATCTGTAAAGGACTA \\
\hline P2: SIFA3F & AATTCTAATACGACTCACTATAGGGGGGAGGTTGTCAGAGCAGAAATCATGAGA \\
\hline \multicolumn{2}{|l|}{ G-protein } \\
\hline P1: SGPROTR & GGTGGGTGATTAACTGCTTGTACA \\
\hline P2: SGPROTF & AATTCTAATACGACTCACTATAGGGAGGCTGACTATGTGCCGAGCGATCA \\
\hline \multicolumn{2}{|l|}{ Enterovirus CBV3 } \\
\hline P1: SCBV3R & ATTGTCACCATAAGCAGCCA \\
\hline P2: SCBV3F & AАTTCTAATACGACTCACTATAGGGAGACATGGTGCGAAGAGTCTA \\
\hline
\end{tabular}

of infected green monkey kidney cells (GMK). RNA isolation was done by QIAamp Viral RNA Mini Kit (Qiagen, Hilden, Germany). The IFN- $\alpha 21$ was amplified from RNA (40 ng) purified from human leukocytes. RNA isolation was done using the PAXgene ${ }^{\mathrm{TM}}$ Blood RNA System (Qiagen) according to manufacturer's instructions. The insulin and G-protein RNA amplification was done using the commercial human pancreas BD Premium Poly-A ${ }^{+}$RNA (5 ng) (BD Biosciences, Palo Alto, CA) as starting material.

\subsection{Inverse NASBA primer design}

Primer design was modified to produce positive strand RNA. Also the complementary region for the detection probe (ECL probe) was left out, which was not needed for this application. Primer sequences are presented in Table 1. P1 primer (reverse primer): the T7 RNA polymerase promoter sequence was not attached to this primer as usually is done for NASBA. The primer was 20-30 nucleotides long, complementary to the target RNA and it had an A at the $3^{\prime}$-end. P2 primer (forward primer): the ECL detection complementary sequence was not added to this primer, instead the T7 RNA polymerase promoter sequence (AATTCTAATACGACTCACTATAGGG) was added to the primer sequence at its $5^{\prime}$-end. The promoter sequence was followed by a 20-30 nucleotides long region identical to the target RNA, it had an A at the 3 -end, and the first 10 nucleotides after the promoter sequence were purine-rich (A or $G$ ). The purine-rich sequence could also be inserted between the promoter sequence and the target RNA sequence. Neither capture nor detection probe was needed.

\subsection{Amplification of control RNA}

RNA amplification was done by inverse NASBA using the NucliSens ${ }^{\circledR}$ Basic Kit (Biomerieux, Marcy l'Etoile, France) according to the manufacturer's instructions. Briefly, $5 \mu l$ of extracted RNA (5-40 ng) was mixed with $10 \mu$ l of reagent mixture containing the Basic Kit reagent mixture, $140 \mathrm{mM} \mathrm{KCl}$ and $1.7 \mu \mathrm{M}$ of each primers (Table 1). This mixture was incubated for $5 \mathrm{~min}$ at $65^{\circ} \mathrm{C}$ and for $5 \mathrm{~min}$ at $41^{\circ} \mathrm{C}$. The Basic Kit enzyme mixture $(5 \mu \mathrm{l})$ was added and incubation at $41^{\circ} \mathrm{C}$ was continued for a further $2-3 \mathrm{~h}$.

The amplified RNA was detected from an $1.5 \%$ agarose gel: $1.5 \mu l$ inverse NASBA reaction mixture, $2 \mu 15 \times$ loading buffer (instructions in PAXgene Blood RNA Kit Handbook, Appendix E) and $6.5 \mu \mathrm{l}$ RNase free water were mixed, heated at $70^{\circ} \mathrm{C}$ for $10 \mathrm{~min}$ and loaded on the gel. The RNA ladder, low range (Fermentas, Burlington, Canada) was heat treated in the same way before loading on the gel.

The amplified RNA was treated with RNase-Free DNase (Qiagen) to digest DNA generated in the NASBA reaction. After amplification, $5 \mu$ l RDD buffer and $1.3 \mu$ l DNaseI stock solution (2.7 Kuniz units/ $\mu \mathrm{l}$ ) were added to the inverse NASBA reaction mixture. RNase free water was added to make the total volume $50 \mu \mathrm{l}$. This mixture was incubated at RT for 45-60 min. After the DNase treatment, the RNA fragment was purified using the NucleoSpin ${ }^{\circledR}$ RNA Clean-Up Kit (Macherey-Nagel GmbH \& Co., Düren, Germany) or from an $1.5 \%$ agarose gel using the QIAquick Gel Extraction Kit (Qiagen) according to instructions.

\subsection{RT-PCR reactions}

The ultra-sensitive enterovirus specific RT-PCR has been described earlier (Lonnrot et al., 1999). The amplified CBV3 control RNA was added in a volume of $10 \mu \mathrm{l}(0.29 \mathrm{pg})$ to the RT reaction mixture (total volume $40 \mu \mathrm{l}$ ) containing the M-MLV reverse transcriptase (Moloney murine leukaemia virus reverse transcriptase, Promega, Madison, WI, USA) and the reverse primer (4-) GAAACACGGACACCCAAAGTA. The mixture was incubated for $1 \mathrm{~h}$ at $37^{\circ} \mathrm{C}$. An amount of $10 \mu \mathrm{l}$ of the RT mixture was added to the PCR reaction (total volume $100 \mu \mathrm{l}$ ) containing the forward (636+) CGGCCCCTGAATGCGGCTAA and reverse (4-) primers and DyNAzyme ${ }^{\mathrm{TM}}$ DNA polymerase (Finnzymes, Espoo, Finland). PCR products were analysed from an $1.5 \%$ agarose gel and by the hybridisation protocol described earlier.

Insulin and G-protein specific RT-PCR has been described previously (Ritz-Laser et al., 2002). The RT reaction for insulin was done in a total volume of $25 \mu \mathrm{l}$ using $10 \mu \mathrm{l}$ of amplified insulin control RNA (0.1-1 ng), random hexamers 
or alternatively the reverse primer AGTAGTTCTCCAGCTGGTAG (INSR), M-MLV reverse transcriptase (Promega) and $1 \mathrm{~h}$ incubation at $37^{\circ} \mathrm{C}$. Insulin cDNA was amplified using $10 \mu l$ of the RT reaction mix, DyNAzyme ${ }^{\mathrm{TM}}$ DNA polymerase (Finnzymes) and following primers: forward CCTTTGTGAACCAACACCTG (INSF) and reverse (INSR). PCR cycles were: hot start at $94{ }^{\circ} \mathrm{C}$ for $3 \mathrm{~min}, 45$ cycles of $94^{\circ} \mathrm{C}$ for $1 \mathrm{~min}, 58^{\circ} \mathrm{C}$ for $1 \mathrm{~min}, 72^{\circ} \mathrm{C}$ for $1 \mathrm{~min}$, and at the end one elongation step at $72{ }^{\circ} \mathrm{C}$ for $7 \mathrm{~min}$.

The RT reaction for G-protein was done in a total volume of $25 \mu \mathrm{l}$ using $10 \mu \mathrm{l}$ of amplified G-protein control RNA (0.1-1 ng), random hexamers or alternatively the reverse primer TTAAGGCTTTAATTAAATTTGGGGGTTCC (GPAR), M-MLV reverse transcriptase (Promega) and $1 \mathrm{~h}$ incubation at $37^{\circ} \mathrm{C}$. G-protein cDNA was amplified using $10 \mu \mathrm{l}$ of the RT-mixture, DyNAzyme ${ }^{\mathrm{TM}}$ DNA polymerase and following primers: forward ACTTCTGGAATCTTTGAGACCAAG (GPAF) and reverse (GPAR). PCR cycles were: hot start at $94^{\circ} \mathrm{C}$ for $3 \mathrm{~min}, 45$ cycles of $94^{\circ} \mathrm{C}$ for $1 \mathrm{~min}, 50^{\circ} \mathrm{C}$ for $1 \mathrm{~min}, 72^{\circ} \mathrm{C}$ for $1 \mathrm{~min}$, and at the end one elongation step at $72{ }^{\circ} \mathrm{C}$ for $7 \mathrm{~min}$.

IFN- $\alpha 21$ specific real-time RT-PCR is based on the Applied Biosystems (Foster City, CA), Assays-on-Demand ${ }^{\mathrm{TM}}$ protocol for IFN- $\alpha 21$. Primers and probes were purchased from Applied Biosystems (Foster City, CA), as was the TaqMan ${ }^{\mathrm{TM}}$ Universal PCR Master Mix. The RT reaction was done in the same way as for insulin and G-protein using random hexamers and 10fold dilutions $(0.02-200 \mathrm{pg})$ of the NASBA amplified control IFN- $\alpha 21$ RNA. IFN- $\alpha 21$ cDNA was amplified by the Applied Biosystems 7900 HT Fast Real-Time PCR System using $5 \mu 1$ RT reaction mixture, TaqMan ${ }^{\mathrm{TM}}$ Universal PCR Master Mix, and Assays-on-Demand ${ }^{\mathrm{TM}}$ Assay Mix for IFN- $\alpha 21$. PCR cycles were as follows: $50^{\circ} \mathrm{C}$ for $2 \mathrm{~min}, 60^{\circ} \mathrm{C}$ for $30 \mathrm{~min}, 95^{\circ} \mathrm{C}$ for $10 \mathrm{~min}$, followed by 40 cycles of $94^{\circ} \mathrm{C}$ for $20 \mathrm{~s}$ and $51^{\circ} \mathrm{C}$ for $1 \mathrm{~min}$.

\section{Results}

Four different RNA products were amplified to be used as positive control material for RT-PCR and real-time RT-PCR. The amplified RNA fragments were 195 bases for enterovirus, 414 bases for insulin, 714 bases for G-protein, and the IFN- $\alpha 21$ fragment was 275 bases long (Fig. 1). Amplified control fragments were designed to produce 81-159 bases longer RNA fragments than the designed RT-PCR fragments. The corresponding RTPCR products were 114, 255, $609 \mathrm{bp}$ (Fig. 2) and approximately $150 \mathrm{bp}$ long, respectively. RT-PCR products were detected from an agarose gel, except the IFN- $\alpha 21$ was detected by TaqMan ${ }^{\mathrm{TM}}$ probe in real-time PCR (Fig. 3). The enterovirus PCR product was additionally detected by liquid hybridisation (Lonnrot et al., 1999) to confirm the specific PCR product, since two bands were detected from the agarose gel.

In addition to using different purified RNAs as a starting material for the inverse NASBA reaction, amplification was tested from the already inverse NASBA amplified G-protein control RNA ( $25 \mathrm{ng}$ ), which resulted in the right RNA fragment detected from agarose gel. This RNA fragment was also amplified by RT-PCR. In addition, the amount of produced

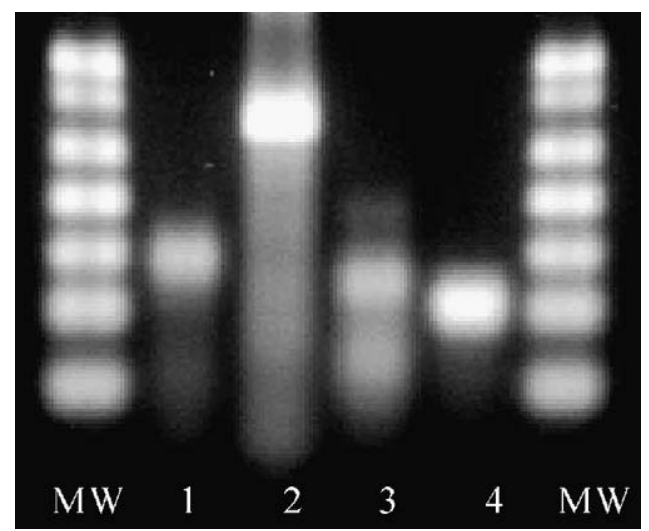

Fig. 1. Agarose gel electrophoresis of amplified inverse NASBA RNA products before purification. The first lane (MW) is a RNA molecular weight marker; the bands represent sizes of 100, 200, 300, 400, 600, 800 and 1000 bases. Lane 1 is the amplified IFN- $\alpha$ (275 bp), lane 2 is the G-protein (714bp), lane 3 is the insulin control (414 bp) RNA and lane 4 is the enterovirus control (195 bp) RNA.

RNA was in the same range as when using purified leukocyte RNA.

The NASBA amplification produces some double stranded DNA as a by-product. Also some remaining DNA:RNA hybrid residues might be present. This DNA can cause false positive results in RT-PCR even when the RT reaction does not work properly. Therefore, the inverse NASBA products were DNase treated. The incubation time was optimised from 10 up to $60 \mathrm{~min}$.

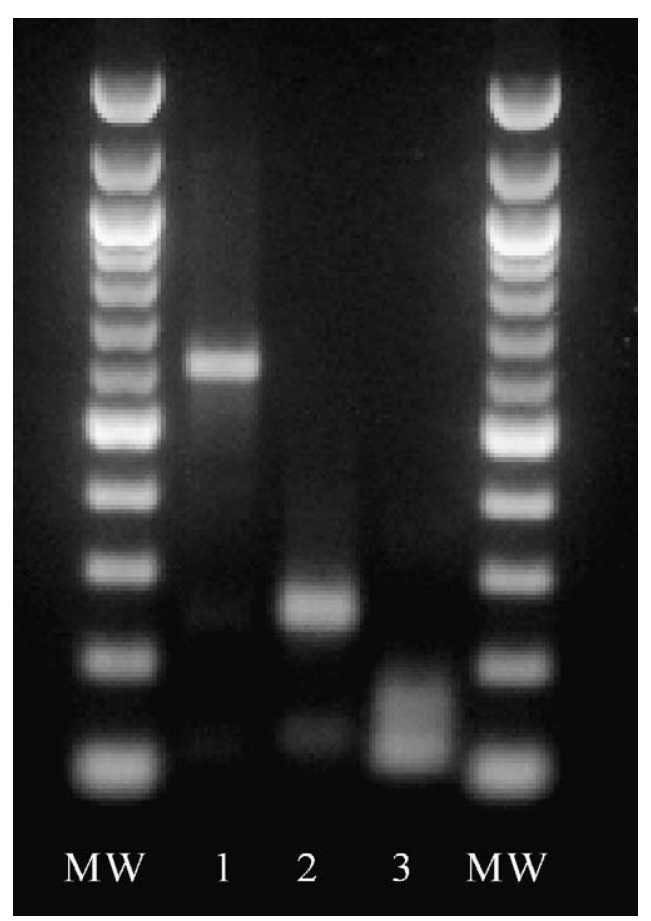

Fig. 2. Agarose gel electrophoresis of RT-PCR products amplified from inverse NABSA RNA products described in Fig. 1. The first lane (MW) is a DNA molecular weight marker, the bands represent sizes of 100, 200, 300, 400, 500/517, $600,700,800,900,1000,1200$ and $1517 \mathrm{bp}$. Lane 1 is the G-protein fragment $(609 \mathrm{bp})$, lane 2 is the insulin product $(255 \mathrm{bp})$ and lane 3 is the enterovirus product (114bp). 


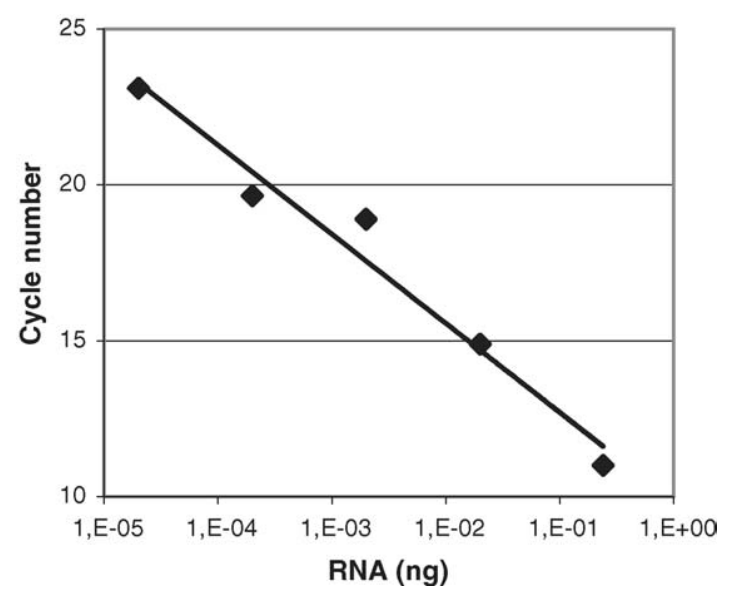

Fig. 3. Standard curve of IFN- $\alpha$ real-time RT-PCR. Ten-fold dilutions of inverse NASBA amplified IFN- $\alpha 21$ RNA $(0.02-200 \mathrm{pg})$ was amplified by real-time RTPCR. The $C_{\mathrm{t}}$ (threshold cycle) values ranged from 11.00 to 23.12.

The longer incubation times, 45-60 min, resulted in a lower amount of DNA, which were not detectable after PCR (without RT) from an agarose gel (Fig. 4). However, in the more sensitive real-time PCR, the residual DNA gave still a signal above the detection limit. The reduction of DNA by DNase treatment was drastic. In the amplified inverse NASBA product, about $5 \%$ was DNA and $95 \%$ was RNA before the DNase treatment. After DNase treatment, the amount of contaminating DNA was reduced to about 1/1,000,000 (calculated values from real-time PCR).

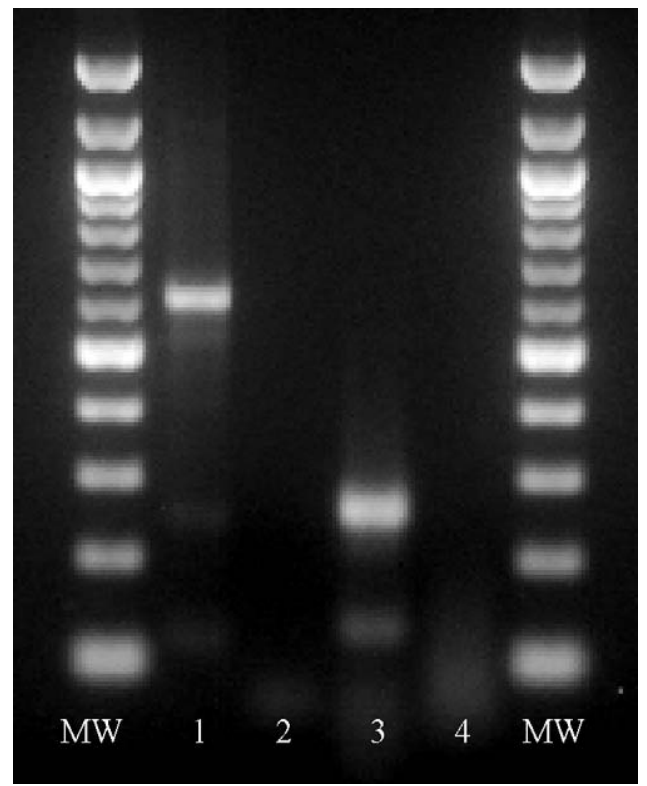

Fig. 4. DNA contamination of inverse NASBA RNA products. After DNase treatment G-protein and insulin RNA was amplified by RT-PCR or only by PCR. Lanes 1 and 2 show G-protein amplification by RT-PCR (1) and PCR (2). Lanes 3 and 4 show insulin amplified by RT-PCR (3) and PCR (4). The absence of PCR products, in contrast to RT-PCR products, proves the DNA concentration to be below detection limit. The DNA molecular weight marker (MW) bands represent sizes of 100, 200, 300, 400, 500/517, 600, 700, 800, 900, 1000, 1200 and $1517 \mathrm{bp}$.

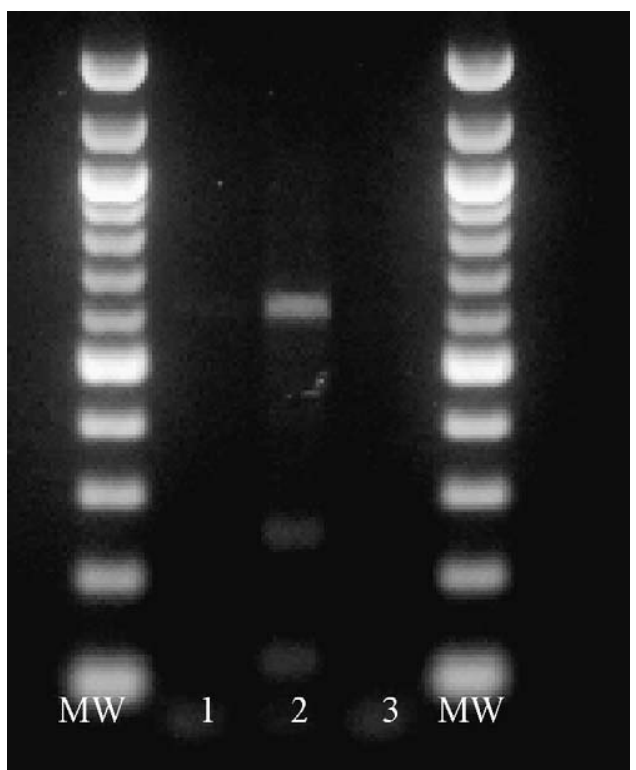

Fig. 5. RNA polarity. Picture shows the positive polarity of the NASBA RNA product. As an example, the G-protein RNA was amplified by RT-PCR using specific primers in the RT reaction. Lane 1 is the negative control, where no primer was added to the cDNA reaction, lane 2 is the cDNA was generated using the reverse primer $(609 \mathrm{bp})$ and lane 3 is the cDNA was generated using the forward primer. The DNA molecular weight marker (MW) bands represent sizes of 100, 200, 300, 400, 500/517, 600, 700, 800, 900, 1000, 1200 and $1517 \mathrm{bp}$.

This amplification protocol after the NucleoSpin ${ }^{\circledR}$ purification resulted in a total amount of 1.3-5.4 $\mu \mathrm{g}$ RNA in a volume of about $58 \mu \mathrm{l}$. This amount of RNA should be sufficient from 10,000 up to a million RT-PCR reactions depending on the sensitivity of the used RT-PCR.

The NucleoSpin ${ }^{\circledR}$ purification was compared to purifying the RNA fragments from an agarose gel and using the QIAquick Gel Extraction Kit. The advantage of the gel purification is that it adds specificity to the RNA product, since NASBA is not very specific due to the thermal amplification where only $41{ }^{\circ} \mathrm{C}$ is used allowing some non-specific amplification. On the other hand, the loss of the RNA product was greater by the gel purification, it produced about 0.3-0.6 $\mu \mathrm{g}$ RNA, which is less than half, at its best, compared to the NucleoSpin ${ }^{\circledR}$ purification. Because of better RNA recovery, the easier protocol and no major negative interference, the NucleoSpin ${ }^{\circledR}$ purification was used.

NASBA produces normally opposite strand RNA to the target. In the present inverse NASBA application, we designed the primers in a way that produces identical RNA strand, which is positive strand in these examples. To show that this is really the case the RT reaction was done using specific primers: reverse primer, forward primer or no primer at all. The result is shown in Fig. 5; only the RT-PCR where the reverse primer was used in the RT reaction was amplified, while there was no amplification when either forward primer or no primer was used in the RT reaction. This shows that there is no negative strand present.

\section{Discussion}

This paper demonstrates how to amplify positive control RNA for RT-PCR applications in excess amounts. It takes 
approximately 3 days to amplify, purify and test the produced control RNA after which it is ready to be used. The amplified amount is sufficient for thousands of RT-PCR reactions. Also amplifying RNA from the earlier amplified control RNA was shown to be possible and to produce about same amounts of RNA as from the original template. This reduces, for example, the handling of infective viruses, since only in the first time amplification the original virus has to be used as a template, after this the amplified control RNA can be used.

The amplified RNA was of positive polarity that is identical to the amplified target (Fig. 5). The contaminating dsDNA or DNA:RNA hybrids generated in the inverse NASBA reaction were reduced to a level where it was not amplified in PCR giving thus no false positive results (Fig. 4).

In conclusion, the inverse NASBA described is an easy and fast way to manufacture your own control RNA for RT-PCR and NASBA. Usually there is no need for optimising the procedure since in these cases sensitivity is not a problem. This method does not need any expensive equipment for amplification or detection. Amplification of RNA is done on a water bath, in a constant temperature, and detection is done using an agarose gel and by testing the RNA produced by RT-PCR.

\section{Acknowledgements}

We want to thank Eeva Tolvanen for technical assistance. This work was supported by JDRF, The Academy of Finland, the Finnish Diabetes Research Foundation and the Finnish Cultural Foundation.

\section{References}

Blok, M.J., Christiaans, M.H., Goossens, V.J., van Hooff, J.P., Top, B., Middeldorp, J.M., Bruggeman, C.A., 1998. Evaluation of a new method for early detection of active cytomegalovirus infections. A study in kidney transplant recipients. Transpl. Int. 11 (Suppl. 1), S107-S109.

Compton, J., 1991. Nucleic acid sequence-based amplification. Nature 350, 91-92.
Cook, N., 2003. The use of NASBA for the detection of microbial pathogens in food and environmental samples. J. Microbiol. Meth. 53, 165174.

de Baar, M.P., van Dooren, M.W., de Rooij, E., Bakker, M., van Gemen, B., Goudsmit, J., de Ronde, A., 2001. Single rapid real-time monitored isothermal RNA amplification assay for quantification of human immunodeficiency virus type 1 isolates from groups $\mathrm{M}, \mathrm{N}$, and O. J. Clin. Microbiol. 39, 1378-1384.

D'Souza, D.H., Jaykus, L.A., 2003. Nucleic acid sequence based amplification for the rapid and sensitive detection of Salmonella enterica from foods. J. Appl. Microbiol. 95, 1343-1350.

Heim, A., Grumbach, I.M., Zeuke, S., Top, B., 1998. Highly sensitive detection of gene expression of an intronless gene: amplification of mRNA, but not genomic DNA by nucleic acid sequence based amplification (NASBA). Nucl. Acid Res. 26, 2250-2251.

Kievits, T., van Gemen, B., van Strijp, D., Schukkink, R., Dircks, M., Adriaanse, H., Malek, L., Sooknanan, R., Lens, P., 1991. NASBA isothermal enzymatic in vitro nucleic acid amplification optimized for the diagnosis of HIV-1 infection. J. Virol. Meth. 35, 273-286.

Lanciotti, R.S., Kerst, A.J., 2001. Nucleic acid sequence-based amplification assays for rapid detection of West Nile and St. Louis encephalitis viruses. J. Clin. Microbiol. 39, 4506-4513.

Loens, K., Ieven, M., Ursi, D., Beck, T., Overdijk, M., Sillekens, P., Goossens, H., 2003a. Detection of Mycoplasma pneumoniae by real-time nucleic acid sequence-based amplification. J. Clin. Microbiol. 41, 44484450 .

Loens, K., Ieven, M., Ursi, D., Foolen, H., Sillekens, P., Goossens, H., 2003b. Application of NucliSens Basic Kit for the detection of Mycoplasma pneumoniae in respiratory specimens. J. Microbiol. Meth. 54, 127-130.

Lonnrot, M., Sjoroos, M., Salminen, K., Maaronen, M., Hyypia, T., Hyoty, H., 1999. Diagnosis of enterovirus and rhinovirus infections by RT-PCR and time-resolved fluorometry with lanthanide chelate labeled probes. J. Med. Virol. 59, 378-384.

Mengoli, C., Cusinato, R., Biasolo, M.A., Cesaro, S., Parolin, C., Palu, G., 2004. Assessment of CMV load in solid organ transplant recipients by pp65 antigenemia and real-time quantitative DNA PCR assay: correlation with pp67 RNA detection. J. Med. Virol. 74, 78-84.

Ritz-Laser, B., Oberholzer, J., Toso, C., Brulhart, M.C., Zakrzewska, K., Ris, F., Bucher, P., Morel, P., Philippe, J., 2002. Molecular detection of circulating $\beta$-cells after islet transplantation. Diabetes 51, 557-561.

Sugiyama, M., Ito, N., Minamoto, N., 2003. Isothermal amplification of rabies virus gene. J. Vet. Med. Sci. 65, 1063-1068.

Wacharapluesadee, S., Hemachudha, T., 2001. Nucleic-acid sequence based amplification in the rapid diagnosis of rabies. Lancet 358, 892-893. 